\title{
15 \\ FORMAÇÃO CONTINUADA DE PROFESSORES DA EDUCAÇÃO INFANTIL EM UM GRUPO DE ESTUDOS: COMPARTILHANDO SABERES SOBRE JOGOS MATEMÁTICOS*
}

\author{
Denise França Stehling \\ Keli Cristina Conti
}

\section{Introdução}

Este capítulo busca trazer excertos do percurso, as análises e os resultados da pesquisa intitulada "Saberes e conhecimentos matemáticos na Educação Infantil: formação continuada de professores em um grupo de estudos" (STEHLING, 2018), apresentada ao Programa de Mestrado Profissional em Educação e Docência da Faculdade de Educação da Universidade Federal de Minas Gerais, na linha de Educação Matemática.

Após ressignificar e recontextualizar o projeto de pesquisa, foi proposto a formação de um grupo de estudos para não só descrever situações problemáticas observadas no cotidiano das práticas pedagógicas, como também ressignificar tais situações, buscando criar espaços de reflexão, de pesquisa e de inovação nas estratégias de aprendizagem referente ao conhecimento matemático na Educação Infantil. Como produto final organizamos, a partir dos encontros e relatos orais e escritos das professoras participantes do grupo de estudos, um e-book (STEHLING; CONTI, 2019), com a perspectiva de constituir um material de viés formativo, compartilhando as descobertas e propondo novos caminhos que avancem na investigação e reflexão das práticas pedagógicas na Educação Infantil.

Para este capítulo selecionamos, a partir da pesquisa, dois objetivos: destacar algumas reflexões sobre o conhecimento matemático na Educação Infantil, por meio de um referencial teórico; e evidenciarmos os saberes e conhecimentos matemáticos e metodológicos mobilizados, reconhecidos e ressignificados por professoras quando se reúnem num grupo de estudos, por meio dos registros das práticas envolvendo "jogos matemáticos" e o que as participantes chamaram de "compartilhando também se aprende" que foi discutido num dos encontros do grupo, destacando os fazeres práticos dos professores.

${ }^{*}$ DOI - 10.29388/978-65-86678-49-9-0-f.251-266 


\section{Alternativas metodológicas e o conhecimento matemático na Educação Infantil}

A proposta pedagógica das instituições de Educação Infantil deve ter como objetivo principal promover o desenvolvimento integral das crianças de zero a cinco anos de idade, garantindo a cada uma delas o acesso a processos de construção de conhecimentos e a aprendizagem de diferentes linguagens, assim como o direito à proteção, à saúde, à liberdade, ao respeito, à dignidade, à brincadeira, à convivência e à interação com outras crianças.

Nesse sentido, esse estudo aponta, entre outras alternativas metodológicas para embasar o conhecimento matemático na Educação Infantil, os jogos.

$\mathrm{Na}$ discussão sobre jogos, encontramos autores como Kishimoto (2016), que distingue o termo jogo, do termo brincadeira e brinquedo. Para a autora, brinquedo é o objeto, o suporte para a brincadeira e pode ser industrializado, artesanal ou fabricado pela própria professora junto com a criança e a sua família. Já a brincadeira pressupõe a descrição de uma conduta estruturada, com regras e jogo refere-se à descrição de uma ação lúdica envolvendo situações estruturadas pelo próprio tipo de material. Esse estudo também compreende que são conceitos diferenciados, ou seja, os jogos e as brincadeiras não são as mesmas coisas.

Parecem conceitos simples, mas há algumas práticas pedagógicas equivocadas envolvendo o brincar, conforme nos alerta Kishimoto (BRASIL, 2012):

A pouca qualidade ainda presente na Educação Infantil pode estar relacionada à concepção equivocada de que o brincar depende apenas da criança, não demanda suporte do adulto, observação, registro nem planejamento. Tal visão precisa ser desconstruída, uma vez que a criança não nasce sabendo brincar. Ao ser educada, a criança deve entrar em um ambiente organizado para recebê-la, relacionar-se com as pessoas (professoras, pais e outras crianças), escolher os brinquedos, descobrir os usos dos materiais e contar com a mediação do adulto ou de outra criança para aprender novas brincadeiras e suas regras. Depois que aprende, a criança reproduz ou recria novas brincadeiras e assim vai garantindo a ampliação de suas experiências. (BRASIL, 2012, p. 8).

Enquanto brinca, a criança pode ser incentivada a realizar contagens, comparação de quantidades, identificar algarismos, adicionar pontos e perceber intervalos numéricos. É também uma oportunidade para perceber distâncias, desenvolver noções de velocidade, duração, tempo, força, altura e fazer estimativas. 
Para Smole, Diniz e Cândido (2000, p. 11), brincar é um modo de obter informações, respostas e contribuir para que a criança adquira uma certa flexibilidade, vontade de experimentar, buscar novos caminhos, conviver com o diferente, ter confiança, raciocinar, descobrir, aprender a perder percebendo que haverá novas oportunidades de ganhar. Importante destacar que nem sempre a atividade lúdica traz prazer. Há atividades em que o desprazer fica caracterizado, como os jogos desportivos em que há um perdedor. Essas duas propostas metodológicas são diferenciadas. Destacamos, principalmente a diferença da ação livre por parte da criança, existente nas brincadeiras. De toda forma, tanto as brincadeiras quanto os jogos, necessitam do planejamento do professor, conforme citado acima Brasil (2012).

Em relação à organização curricular, este estudo foi realizado anteriormente à implantação da Base Nacional Comum Curricular (BNCC) está em conformidade com o Referencial Curricular Nacional para a Educação Infantil (RCNEI), embora bastante questionado, (BRASIL, 1998), as DCNEI (BRASIL, 2009) e os documentos oficiais do MEC comos cadernos Brinquedos e brincadeiras nas creches (BRASIL, 2012) e a Coleção Leitura e Escrita na Educação Infantil (BRASIL, 2016).

De acordo com o RCNEI “[...] as crianças, desde o nascimento, estão imersas em um universo do qual os conhecimentos matemáticos são parte integrante" (BRASIL, 1998, p. 207). E de acordo com o documento,

O jogo pode tornar-se uma estratégia didática quando as situações são planejadas e orientadas pelo adulto visando a uma finalidade de aprendizagem, isto é, proporcionar à criança algum tipo de conhecimento, alguma relação ou atitude. Para que isso ocorra, é necessário haver uma intencionalidade educativa, o que implica planejamento e previsão de etapas pelo professor, para alcançar objetivos predeterminados e extrair do jogo atividades que lhe são decorrentes. (BRASIL, 1998, p. 211)

No que diz respeito aos jogos, o RCNEI aponta também que:

A educação infantil, historicamente, configurou-se como o espaço natural do jogo e da brincadeira, o que favoreceu a idéia de que a aprendizagem de conteúdos matemáticos se dá prioritariamente por meio dessas atividades. A participação ativa da criança e a natureza lúdica e prazerosa inerentes a diferentes tipos de jogos têm servido de argumento para fortalecer essa concepção, segundo a qual aprende-se Matemática brincando. (BRASIL, 1998, p. 210-211) 
Conforme texto introdutório do RCNEI, o âmbito conhecimento de mundo, contém seis documentos referentes aos eixos de trabalho orientados para a construção das diferentes linguagens pelas crianças e para as relações que estabelecem com os objetos de conhecimento: movimento, música, artes visuais, linguagem oral e escrita, natureza e sociedade e matemática. Embora tenhamos um conjunto de linguagens, nosso destaque nesse estudo foi apenas para a Matemática.

A linguagem matemática foi apresentada no RCNEI (BRASIL, 1998) com os seguintes tópicos: Introdução; Presença da Matemática na Educação Infantil: ideias práticas e correntes; A criança e a Matemática: apresentados em três blocos: (1) Números e sistema de numeração, (2) Grandezas e medidas e (3) Espaço e forma; Orientações gerais para o professor: Jogos e brincadeiras, organização do tempo, observação, registro e avaliação formativa.

Teóricos como Lorenzato (2011) apontam ainda que o trabalho com noções matemáticas na Educação Infantil traz resultados no desenvolvimento e estímulo aos processos mentais. Crianças aprendem observando, explorando e enfrentando situações-problema relacionadas às ideias e processos de natureza matemática como contar, localizar, medir, desenhar, jogar e explicar.

Em relação à Educação Infantil e ao conhecimento matemático, acreditamos que nos primeiros dias de vivências e experiências na Educação Infantil, é imprescindível que o professor investigue o que as crianças compreendem sobre números, espaço e medidas. Nesse contexto, Lorenzato (2011) afirma que:

Toda criança chega à pré-escola com alguns conhecimentos e habilidades no plano físico, intelectual e socioafetivo, fruto de sua história de vida. Essa bagagem, que difere de criança para criança, precisa ser identificada pelo professor. (LORENZATO, 2011, p. 24).

Nessa perspectiva, o autor sugere que a base da proposta de um trabalho matemático se sustente em três campos:

$1^{\circ}$ ) aproveitar os conhecimentos e habilidades de que as crianças são portadoras; medidas);

$2^{\circ}$ ) explorar os três campos matemáticos (espacial, numérico e

$3^{\circ}$ ) começar o trabalho pelas noções.

Lorenzato (2011) sugere que essas noções devem ser revisadas ou introduzidas verbalmente e por meio de diversas situações, visando trabalhar com materiais manipulativos, desenhos e histórias. O autor afirma que o trabalho deve se sustentar nos três campos citados acima e iniciar nos 
ambientes de práticas pedagógicas na Educação Infantil, a partir das noções que ele organizou em três grupos:

Quadro 1: Noções matemáticas

\begin{tabular}{|ccc|}
\hline \multicolumn{3}{|c|}{ NOÇÕES MATEMÁTICAS } \\
\hline $\begin{array}{c}\text { grande/pequeno } \\
\text { maior/menor }\end{array}$ & mais/menos & aberto/fechado \\
grosso/fino & igual/diferente & em cima/embaixo \\
direita/esquerda \\
curto/comprido & dentro/fora & primeiro/último/entre \\
alto/baixo & começo/meio/fim & na frente/atrás/ao lado \\
largo/estreito & antes/agora/depois & para frente/atrás/ao lado \\
perto/longe & cedo/tarde & para a direita/para a esquerda \\
leve/pesado & dia/noite & para cima/para baixo \\
vazio/cheio & ontem/hoje/amanhã & ganhar/perder \\
& devagar/depressa & aumentar/diminuir \\
& & \\
\end{tabular}

Fonte: LORENZATO, 2011, p. 24

A escolha por materiais manipulativos deve ser intencional e ter como objetivo uma observação concreta nas vivências, experiências e nos jogos realizados pelas crianças para auxiliá-las na busca de estratégias mentais diferenciadas para que construam o conceito de número e desenvolvam outras habilidades/capacidades. É consenso entre especialistas, que a Matemática é um importante instrumento de leitura e intervenção no mundo em que vivemos. Ler e escrever o mundo, inclui ler o mundo matematicamente também.

Nesse aspecto, o mais importante no uso do material manipulativo é ter em mente sua contribuição na construção do conceito de número e das ideias das operações matemáticas abordadas no contexto infantil, sem preocupar-se com a sistematização de algoritmos.

Quanto aos resultados, espera-se que a criança se interesse cada vez mais pela investigação e exploração matemática em três campos aparentemente independentes: o espacial, das formas, que apoiará o estudo da geometria; o numérico, das quantidades, que apoiará o estudo da aritmética; e o das medidas, que desempenhará a função de integrar a geometria com a aritmética. Ao se apropriarem de um modo de organização, mesmo que induzido pelos adultos, as crianças estão aceitando e incorporando princípios de natureza lógica.

Seja qual for a noção ou o campo matemático (espaço, número, medida) que estiver sendo trabalhado, haverá sempre uma relação direta com um dos conceitos físico-matemáticos seguintes, de acordo com Lorenzato (2011, p. 25): 
Quadro 2: Conceitos físicos matemáticos

\begin{tabular}{|cccc|}
\hline \multicolumn{4}{|c|}{ CONCEITOS FÍSICOS MATEMÁTICOS } \\
\hline Tamanho & Quantidade & posição & volume comprimento \\
lugar & número & medição & massa \\
distância & capacidade & operação & \\
forma & tempo & direção & \\
& & & \\
& & & \\
\hline
\end{tabular}

Fonte: LORENZATO, 2011, p. 25

Lorenzato (2011), ainda defende a necessidade de manter o trabalho com as noções básicas da aritmética. Ele ressalta que, para o professor ter sucesso na organização de situações que propiciem a exploração matemática pelas crianças, é fundamental que ele conheça os sete processos mentais básicos para aprendizagem do conceito de número. De acordo com Lorenzato (2011) os sete processos são:

$\checkmark \quad$ Correspondência: é o ato de estabelecer a relação um a um.

$\checkmark \quad$ Comparação: é o ato de estabelecer diferenças ou semelhanças.

$\checkmark$ Classificação: é o ato de separar em categorias de acordo com semelhanças ou diferenças.

$\checkmark \quad$ Sequenciação: é o ato de fazer suceder a cada elemento um outro sem considerar a ordem entre eles.

$\checkmark \quad$ Seriação: é o ato de ordenar uma sequência segundo um critério.

$\checkmark \quad$ Inclusão: é o ato de fazer abranger um conjunto por outro.

$\checkmark \quad$ Conservação: é o ato de perceber que quantidade não depende da arrumação, forma ou posição.

Esses processos têm o objetivo de dar a conhecer o nível que as crianças se encontram na aquisição de determinados conceitos matemáticos e, nunca foram pensados como tarefas a serem realizadas nas instituições de Educação Infantil. A observação do desenvolvimento desses processos é útil para a orientação das professoras no sentido de proporem questionamentos, vivências e experiências adequadas para que as crianças entrem em conflito com conhecimentos que possuem, visto que aprender matemática é construir significados e sentidos lógicos. Lorenzato (2011, p. 25) afirma ainda que, "[...] sem o domínio desses processos, as crianças poderão até dar respostas corretas, segundo a expectativa e a lógica dos adultos, mas certamente sem significado ou compreensão para elas". 
Nesse instante, o olhar do professor pode ser crucial e desempenhar um papel importante, pois para construir o conceito de número, além de aprender a contar, as crianças devem ser estimuladas a seriar, estabelecer correspondência, classificar, nomear, simbolizar e agrupar. $\mathrm{Na}$ maioria das vezes, essas ações aparecem espontaneamente em vivências cotidianas ou em brincadeiras, pois a Matemática está diretamente envolvida em atividades humanas.

O destaque reside na intencionalidade e na medida em que o professor deve propiciar isso em seu planejamento, ou seja, o destaque se estabelece no ensino.

\section{Caminhos metodológicos da pesquisa}

A estratégia metodológica delineada nessa pesquisa foi o processo colaborativo, com envolvimento da pesquisadora e das professoras participantes buscando reflexão e discussão sobre as práticas pedagógicas e o conhecimento matemático. Essa pesquisa foi desenvolvida com abordagem qualitativa, que de acordo com Bogdan e Biklen (1994), possui cinco características:

$\mathrm{Na}$ investigação qualitativa a fonte direta de dados é o ambiente natural, constituindo o investigador o instrumento principal;

A investigação qualitativa é descritiva;

Os investigadores qualitativos interessam-se mais pelo processo do que simplesmente pelos resultados ou produtos;

Os investigadores qualitativos tendem a analisar os seus dados de forma indutiva;

O significado é de importância vital na abordagem qualitativa (BOGDAN; BIKLEN, 1994, p. 47-50).

Nesse sentido, foi proposta a seguinte questão de investigação: Quais os saberes e conhecimentos matemáticos e metodológicos mobilizados, reconhecidos e ressignificados por professores da Educação Infantil, da Rede Municipal de Ensino de Belo Horizonte, quando se reúnem em grupo de estudos?

Tivemos como objetivo na pesquisa analisar as práticas pedagógicas relatadas por professores em um contexto de grupo de estudos, buscando entender situações problemáticas dos professores no que tange o conhecimento matemático na Educação Infantil.

Para este capítulo, tivemos como objetivo destacar algumas reflexões sobre o conhecimento matemático na Educação Infantil, por meio de um referencial teórico; e evidenciarmos os saberes e conhecimentos matemáticos e 
metodológicos mobilizados, reconhecidos e ressignificados por professoras quando se reúnem num grupo de estudos, por meio dos registros das práticas envolvendo "jogos matemáticos" e o que as participantes chamaram de "compartilhando também se aprende" que foi discutido num dos encontros do grupo, destacando os fazeres práticos dos professores.

A ideia de formação de um grupo de estudos parte do princípio de experimentar, viver e construir coletivamente o saber e o conhecimento, interessando mais os processos do que simplesmente os resultados ou produtos. Experiência sendo compreendida nesse estudo como o processo de se deslocar ao sentir a vivência, ou propiciar reflexões que proponham mudanças ou transformações. Em Stehling (2018), podem ser encontrados mais detalhes sobre as atividades de campo e os instrumentos de registro das informações.

Ao finalizarmos o projeto de pesquisa e com a aprovação no comitê de ética ${ }^{1}$, iniciamos um diálogo com a Secretaria Municipal de Educação por meio de uma gerente de Educação Infantil. Em um encontro pessoal na Secretaria Municipal de Educação (SMED), conversamos sobre objetivos da pesquisa, metodologia e principalmente sobre a proposta da formação de um grupo de estudos com professores. $\mathrm{O}$ projeto de pesquisa foi encaminhado ao gabinete da secretária de educação que autorizou o envio do convite para vinte e sete instituições de Educação Infantil da Rede parceira (creches conveniadas) e Rede própria: Escola Municipal de Educação Infantil (EMEI) e Unidade Municipal de Educação Infantil (UMEI) de ensino de Belo Horizonte, por meio de um ofício.

A escolha das instituições se deu de forma aleatória utilizando uma listagem pública geral disponível no portal da PBH contendo 127 (cento e vinte e sete) Unidades Municipais de Educação Infantil (UMEIs), 13 (treze) Escolas Municipais de Educação Infantil (EMEIs) e 195 (cento e noventa e cinco) creches conveniadas, que compõem a rede parceira, conforme informação do portal $\mathrm{PBH}$, acessado em agosto de 2017. O único critério estabelecido foi o envio de convite para três instituições de cada regional da cidade ${ }^{2}$ : Barreiro, Centro Sul, Leste, Nordeste, Noroeste, Norte, Oeste, Pampulha e Venda Nova. O ofício foi então enviado e com autorização de contato com as instituições. Também enviamos um e-mail às instituições convidando professores para participarem da pesquisa.

\footnotetext{
${ }^{1}$ A pesquisa foi aprovada pelo COEP-UFMG com Certificado de Apresentação para Apreciação Ética (CAAE) 7708 3517.9.0000.5149.

${ }^{2}$ Criadas em 1983, as regionais de Belo Horizonte são espécies de subprefeituras, encarregadas dos bairros de cada uma das nove regiões em que a cidade está subdividida administrativamente. A jurisdição das unidades administrativas regionais leva em conta a posição geográfica e a história de ocupação.
} 
Importante destacar que a participação do grupo de estudos ocorreu em seus horários de trabalho, e a adesão foi livre. Foram propostos sete encontros com três horas de duração cada um, com frequência periódica semanal e acontecendo no turno da tarde, nos meses de outubro, novembro e dezembro de 2017.

O grupo de estudos iniciou seus encontros em 19 de outubro de 2017, com nove professoras presentes e finalizou sete encontros depois, com oito participantes, tendo a descrição de todos os encontros em Stehling (2018). Importante destacar que o papel da pesquisadora foi implementar, ou seja, constituir um processo de mediação que possibilitasse a discussão e o desenvolvimento dos conhecimentos matemáticos, problematizando situações por meio de questões e discussões teóricas sobre as práticas pedagógicas relatadas pelas professoras participantes. Outra estratégia abordada no percurso da pesquisa foi a leitura de textos para a compreensão e superação das dificuldades das práticas pedagógicas relatadas, despertando nas participantes um motivo para modificarem sua postura pedagógica.

Em um dos encontros do grupo, por meio de formulário, levantamos dados a respeito das participantes (quadro 4) ${ }^{3}$ :

Quadro 3: Perfil das professoras

\begin{tabular}{|l|c|c|c|l|}
\hline NOME & TURMA & $\begin{array}{c}\text { ANOS DE } \\
\text { ATUAÇÃO NA } \\
\text { EDUCAÇÃO } \\
\text { INFANTIL }\end{array}$ & IDADE & ESCOLARIDADE \\
\hline Adriana & 5 anos & 14 & 45 anos & Superior/Pedagogia \\
\hline Andriza & 4 anos & 18 & 40 anos & Ensino Médio \\
\hline Auremi & 5 anos & 5 & 44 anos & Superior \\
\hline Elisangela & 5 anos & 9 & 41 anos & Superior/Pedagogia \\
\hline Jane & 4 anos & 1 & 39 anos & Superior/Letras \\
\hline Lílian & 5 anos & 5 & 41 anos & Superior Normal \\
\hline Paula & Não informado & 6 & 53 anos & Superior/Pedagogia \\
\hline Rosemary & 5 anos & 2 & 40 anos & Superior/Pedagogia \\
\hline
\end{tabular}

Fonte: Elaborado pelas pesquisadoras

A próxima sessão apresenta excertos dos encontros do grupo, destacando as discussões a respeito dos jogos. Ainda apresenta análises de como o grupo foi se consolidando como espaço de formação e compartilhamento de práticas, bem como busca a valorização dos saberes e

\footnotetext{
${ }^{3}$ As participantes foram consultadas e assinaram autorização para que os nomes próprios fossem mantidos no texto da dissertação e do produto educacional.
} 
conhecimentos decorrentes de situações envolvendo o conhecimento matemático nas práticas pedagógicas e na complexidade do cotidiano das instituições de Educação Infantil.

\section{O trabalho de campo}

Ao longo do trabalho de campo, ocorreram 7 encontros: Primeiro encontro - intitulado posteriormente para a pesquisa como "Para pensar a prática", sobre a medida de tempo e seus registros; segundo encontro intitulado "Tempo para ir mais devagar" foi sobre quantidades e a construção do número, além da medida de tempo; terceiro encontro - intitulado "Tudo é conjunto", a discussão continuou sobre as quantidades; quarto encontro intitulado "Despertando para outras coisas" que teve como foco a exploração da medida de comprimento; quinto encontro - intitulado "A gente acha que é fácil", em que foram discutidos "espaço e forma"; o sexto encontro - intitulado "Eu consegui" e esteve centrado nas propostas curriculares; o sétimo encontro - intitulado "Compartilhando também se aprende" e versou sobre jogos, além de ser o encontro de encerramento da pesquisa. Embora os encontros tivessem um foco, muitas outras reflexões surgiram, a respeito de currículo, condições de trabalho, políticas públicas, planejamento, angústias, entre outros.

Aqui, destacaremos momentos que fizeram parte do quinto e sétimo encontros respectivamente, iniciando pelo relato da professora Lílian com o jogo "Quebra ovos”,

Lílian: A atividade que eu queria passar foi a da casquinha de ovo. Eu separei, pedi lá na UMEI para separarem umas casquinhas de ovos e aí fiz as bolinhas com as quantidades nas casquinhas e trabalhei com dado. Como lá na sala eles estão muito espertinhos, eu trabalhei com dois dados. Esse de quantidade e esse de numeral (colocando sobre a mesa dois dados confeccionados em caixas grandes). Como eles são muito espertos, eu achei que só com esse aqui (dado de quantidade) seria muito fácil para eles. O quê que eles tinham que fazer? Eles tinham que jogar o dado (da quantidade). Por exemplo, saiu o cinco e eles tinham que achar o numeral 5, aqui no dado de numeral, pegar o martelinho e quebrar a casquinha de ovo, procurando a quantidade que saiu. (Arquivo de vídeo da pesquisadora intervalo 0:47:00 a 0:47:55). 
Figura 1: Fotografia apresentação do jogo "Quebra ovos"

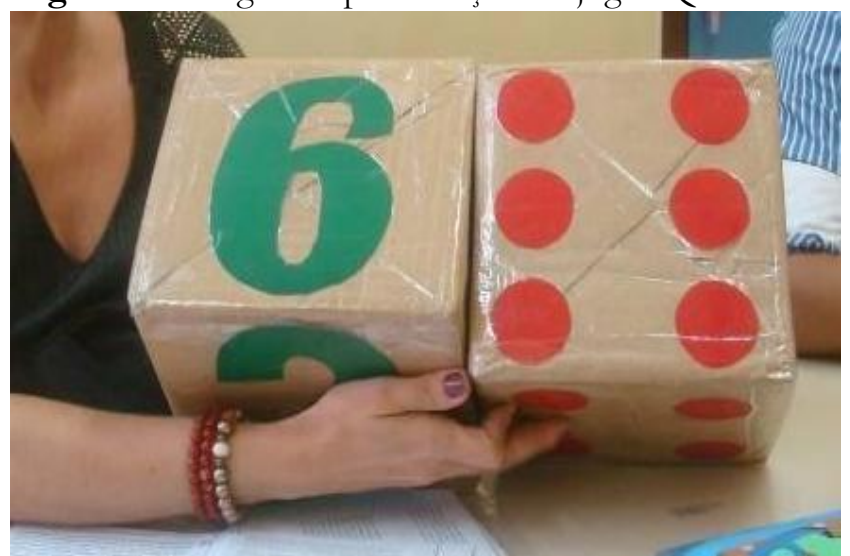

Fonte: Arquivo das pesquisadoras

Discutimos, conversamos e exploramos as possibilidades e variações para iniciar o jogo e depois para dificultá-lo. Lílian disse que faz uma roda e cada criança pode jogar duas vezes. Para iniciar o jogo, colocam-se muitas casquinhas partidas ao meio e o martelinho de plástico em uma bandeja grande. Várias perguntas surgiram principalmente sobre o momento em que a criança quebra a casquinha do ovo relacionando a quantidade ao numeral sorteado no dado.

Adriana e Rosemary perguntaram se as crianças estavam quebrando mais de uma casquinha, ao procurarem a quantidade sorteada no dado. Por exemplo, duas metades, para encontrar a quantidade seis. A professora Lílian disse que sua turma com crianças de cinco e seis anos ainda não despertou para agrupamentos no momento de resolver esse desafio levantado pelo grupo.

Rosemary: Ah, se acabar o seis, eles arrumam um jeito! Não ficam sem brincar.

Adriana: Seria bom deixar eles descobrirem natural, um tempo brincando, brincando e brincando ....

Rosemary: Sempre tem um que resolve! O que quebrar duas ou três casquinhas, pra ele vai ser mais novidade ainda até chegar no seis. Ele vai adorar encontrar e quebrar mais quantidade de casquinha.

Adriana: Eu acho que quando eles descobrirem isso eles vão gostar demais! Eles vão até começar a quebrar três, sabe? Soma de três casquinhas! Eles vão gostar de quebrar cada vez mais casquinhas.

Auremi: Se a gente quiser numerais mais altos é só usar dois dados.

Rosemary: Isso mesmo usar dois dados e eles vão ter que achar e juntar. 
Adriana: Eu acho que quando eles descobrirem isso o que pode fazer, eles vão querer somar até soma de três parcelas e até de quatro. (Arquivo de vídeo da pesquisadora intervalo 0:50:52 a 0:52:30).

Muito interessante como as professoras se envolveram com a reflexão sobre o jogo e a construção do conceito de número. As possibilidades apresentadas dão indícios de mudança na análise da vivência do jogo com as crianças. Abordamos ainda a importância de proporcionarmos às crianças vivências em espaços com liberdade para problematizar e discutir ideias, estabelecendo relações entre conhecimento matemático.

Ouvimos a apresentação de oito jogos, com explicação dos objetivos específicos de cada jogo e apresentação do material. Seguem os relatos sobre os jogos, algumas fotografias do material apresentado e utilizado pelas professoras.

$\checkmark$ Jogo das bolinhas: o objetivo desse jogo é completar as casas de acordo com a sequência criteriosa de cores da cartela.

Figura 2: Fotografias do "Jogo das bolinhas"
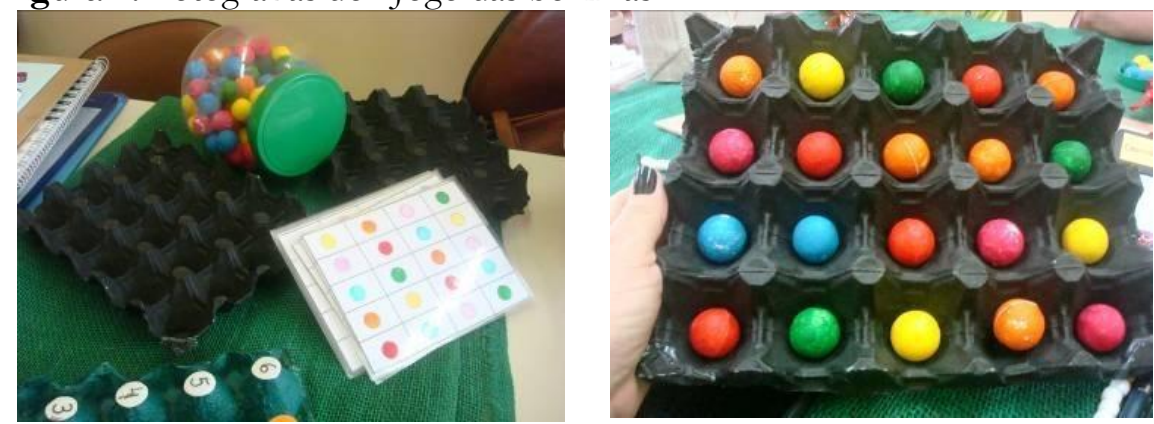

Fonte: Arquivo das pesquisadoras

$\checkmark$ Jogo da trilha colorida: joga-se em grupo de cinco crianças, cada criança escolhe uma cor (branca, laranja, azul, marrom ou amarela). Cada criança joga o dado de cores e se sair sua cor, avança na trilha. Quem terminar primeiro a trilha, é o vencedor. Se o dado foi lançado e cair na cor preta, a criança passa a vez. 
Figura 3: Fotografias do "Jogo da trilha colorida"
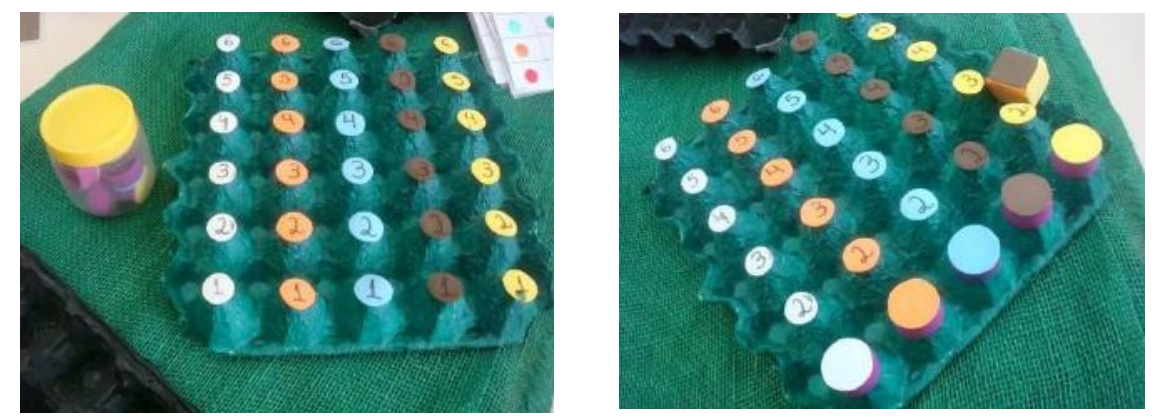

Fonte: Arquivo das pesquisadoras

$\checkmark$ Jogo com sequência numérica: o objetivo desse jogo é encaixar as tampinhas numeradas até a quantidade trinta, seguindo a sequência dos algarismos.

Figura 4: Fotografias do jogo com sequência numérica:
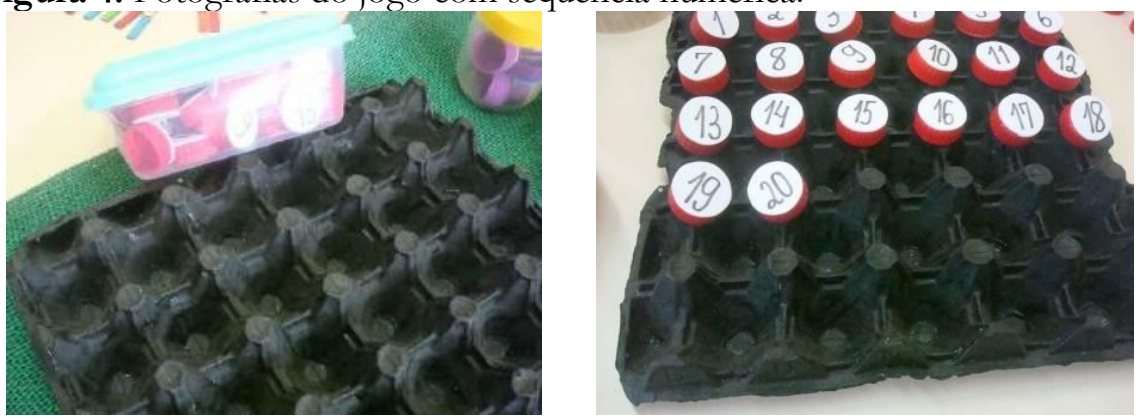

Fonte: Arquivo das pesquisadoras

$\checkmark$ Dominó com palitos coloridos: o objetivo é ordenar os palitos recebidos aleatoriamente de acordo com as cores ordenadas. A criança poderá criar qualquer figura utilizando os palitos, desde que obedeça a sequência das cores. 
Figura 5: Fotografias do dominó com palitos coloridos
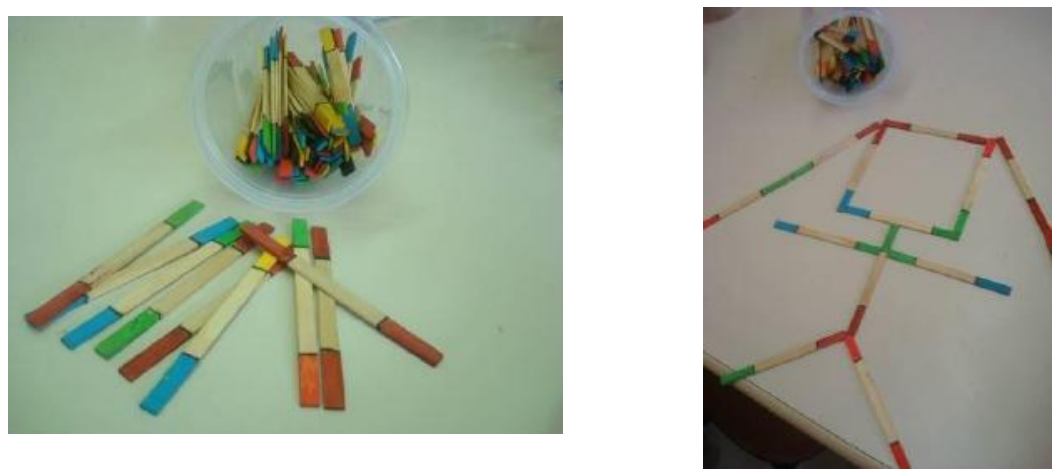

Fonte: Arquivo das pesquisadoras

Ao final, todas as participantes elogiaram bastante, fizeram várias perguntas, como também discutiram possibilidades de adaptações nos jogos apresentados. Auremi e Andriza destacaram que apresentaram os jogos na Mostra Cultural da UMEI e as famílias avaliaram e participaram de todos os jogos propostos. Importante destacar a participação das famílias pensando numa instituição capaz de abrir-se à totalidade da população, inserindo todos os segmentos e não excluindo-os. Enquanto pesquisadoras, acreditamos que esse deve ser o sentido político da ação dos professores para toda a comunidade escolar oportunizando a presença de todos constituindo em um avanço enorme do ponto de vista da democratização efetiva do ensino.

Discutimos ainda sobre os desafios propostos nos jogos quanto à organização das crianças e sobre a diversidade do material utilizado. Analisamos o papel e a criação de jogos não-estruturados para o desenvolvimento de alguns conceitos matemáticos e para o estímulo aos processos mentais, conforme abordado anteriormente. Comentamos também como a aplicação dos jogos contribui para avaliação do professor e pode até mesmo substituir uma avaliação xerografada, se apresentada com contexto. Para finalizar esse momento, Andriza leu um breve relato que as duas escreveram para nosso caderno de memórias. Enquanto lia, Andriza fez alguns comentários sobre o grupo de estudos, como o destacado abaixo:

Andriza: A gente não entendia muito, né, Auremi? Não via isso na parte teórica! Aí a gente viu que tudo isso que a gente faz se encaixa aqui: correspondência, comparação, classificação, seriação... (Arquivo de vídeo da pesquisadora intervalo 0:44:08 a 0:44:33). 
Essa fala da professora Andriza reflete bem a proposta dos encontros, pois destaca como o professor deve pensar sua prática como objeto de estudo, tratando-se da maior ênfase da formação continuada em um grupo de estudos dentro de um contexto colaborativo. Importante destacarmos a existência de uma estreita relação da formação de professores com a construção do conhecimento em relação à profissão e à natureza da função a ser desempenhada.

\section{Algumas considerações}

Ao finalizarmos os encontros compreendemos e avaliamos que o grupo de estudos se constituiu como espaço formativo permitindo as descrições de situações problemáticas envolvendo o conhecimento matemático. Aqui em especial, nosso destaque foi para as discussões e os registros das práticas envolvendo os jogos, destacando os fazeres práticos dos professores. Aos poucos, identificamos indícios de que os saberes e conhecimentos das professoras foram mobilizados, reconhecidos e ressignificados durante a manutenção do grupo. Ouvir a fala de cada professora participante trouxe outro significado para as análises dos encontros, o que constituiu parte do planejamento metodológico deste estudo.

A partir das narrativas das professoras participantes, os momentos vividos foram registrados e culminaram na produção de um e-book (STEHLING; CONTI, 2018) ${ }^{4}$, constando os relatos orais e escritos das professoras participantes do grupo de estudos. Esse editorial vislumbra ser um material de viés formativo, que pretende compartilhar as descobertas contribuindo para avanços na investigação e reflexão das práticas pedagógicas, no que se refere ao conhecimento matemático.

Ao trabalharem o conhecimento matemático com as crianças, observamos que os relatos orais e escritos, sobre a prática, refletiam essa aprendizagem da docência combinando áreas de diferentes conteúdos, demonstrando o caráter transdisciplinar presente nas vivências e experiências da Educação Infantil. As participantes do grupo de pesquisa relataram diversas situações envolvendo outros conhecimentos adquiridos ao longo de sua formação e, que são diariamente mobilizados em suas práticas pedagógicas.

4 Disponível para ser baixado gratuitamente em: https://promestre.fae.ufmg.br/recursoseducacionais/ 


\section{Referências}

BOGDAN, R. C.; BIKLEN, S. K. A Investigação Qualitativa em Educação. Porto: Porto Editora, 1994.

BRASIL. Ministério da Educação e do Desporto. Referencial Curricular Nacional para a Educação Infantil. Brasília: MEC/SEF, 1998.

BRASIL. Conselho Nacional de Educação Câmara de Educação Básica. Resolução CNE/CEB 05/2009 que fixa as Diretrizes Curriculares Nacionais para a Educação Infantil. Diário Oficial da União: seção 1, Brasília, p. 18, 18 dez. 2009.

BRASIL. Ministério da Educação. Secretaria de Educação Básica. Brinquedos e brincadeiras de creches: manual de orientação pedagógica. Ministério da Educação. Secretaria de Educação Básica. Brasília: MEC/SEB, 2012.

BRASIL. Ministério da Educação. Ser docente na Educação Infantil: entre o ensinar e o aprender. 1. ed. Brasília: MEC/SEB, 2016. 128 p.

KISHIMOTO, T. M. Brinquedos e brincadeiras na Educação Infantil. In: BRASIL. Ministério da Educação. Ser docente na educação infantil: entre o ensinar e o aprender. 1 ed. Brasília: MEC/SEB, 2016. p. 128.

LORENZATO, S. Educação Infantil e percepção matemática. 3. ed. Campinas: Autores Associados, 2011.

SMOLE, K. S.; DINIZ, M. I.; CÂNDIDO, P. Matemática de 0 a 6. Porto Alegre: Artmed, 2000 e Penso, 2014.

STEHLING, D. F. Saberes e conhecimentos matemáticos na Educação Infantil: formação continuada de professores em um grupo de estudos. 2018. Dissertação (Mestrado em Educação e Docência) — Faculdade de Educação, Universidade Federal de Minas Gerais, Belo Horizonte, 2018.

STEHLING, D. F.; CONTI, K. C. A arte da palavra: ressignificando o vivido. Belo Horizonte: FaE/UFMG, 2019. 